\title{
Two Cases; Extra-articular Synovial Chondromatosis of Flexor Compartments of the Wrist
}

\author{
(D) Ibrahim Karaman ${ }^{1}$, (D) Ibrahim Halil Kafadar1, (D) Ali Eray Günay² \\ 1 Erciyes University Faculty of Medicine, Department of Orthopaedics and Traumatology, Kayseri, Turkey \\ ${ }^{2}$ Kayseri City Hospital, Clinic of Orthopaedics and Traumatology, Kayseri, Turkey
}

\section{Abstract}

Synovial chondromatosis is a benign synovial neoplasm. Its main characteristic is the formation of cartilaginous nodules in synovial joints, bursae and tendon sheath. It usually presents between the third and fifth decades. The most affected joints are knees, hips, elbow and shoulders; it usually affects only one joint. Patients usually complain of painless mass or swelling, and also reduced range of motion or joint blockage. We present two cases of extra-articular involvement of synovial chondromatosis in the flexor compartments of the wrist. Keywords: Gelatin-like foreign bodies, tendon sheath, carpal tunnel, wrist tumors, synovial tumors

\section{INTRODUCTION}

Synovial chondromatosis is a rare neoplasm that is caused by metaplasia of the synovium into chondrocytes (1). Secondary calcification and ossification commonly occur. The etiology remains unclear and the most common site is in the large joints, predominantly the knee ( $40 \%$ of cases) followed by hip and shoulder, rarely affecting the wrist joint (2-4).

Traumatism and infections along with fibroblast growth factors have been implicated in the pathogenesis $(5,6)$. The extra-articular form develops from tendon sheaths or articular membranes and it affects mainly the hand and wrist structures $(7,8)$. These cases describe an unusual synovial chondromatosis involving the flexor compartments of the wrist, an extra-articular location.

\section{CASE 1}

Fifty nine years old male patient admitted to out-patient clinic with enlarging mass on volar side of his left wrist for 3 years. Patient was complaining about the numbness in the distribution of median nerve and local swelling without pain. Detailed history revealed that he was aware of the lump for 2 years, but severity of the numbness became prominent for 4 months. Numbness and tingling sensation were varying in intensity and present at different times of the day. In physical examination, $15 \times 5 \mathrm{~cm}$ lump at the level of flexor retinaculum was noted. Prominent hypoesthesia in the distribution of median nerve was stated and minimal pain was present with provoked hyperextension of the wrist. Evaluation of the wrist range of motion conducted significant multi-planar restriction.

No specific findings were present in conventional anteroposterior (AP) and lateral radiography except minor soft tissue swelling (Figure 1). Magnetic resonance imaging (MRI) evaluation stated that $12 \times 4 \mathrm{~cm}$ multiple fusiform shaped nodules were surrounding the flexor tendons and filling the carpal tunnel, nodules were hyperintense in T1 weighted images and isointense in $\mathrm{T} 2$ weighted images (Figure 2).

The patient underwent resection surgery by the light of clinical evaluation. Volar approach to the carpal tunnel was preferred. Following the deep dissection, surrounding sac shaped mass is removed and intraoperative puncture of the sac exposed many chondroid nodules. Histopathologic examination revealed chondroid nodules covered with synovial and fibrous cells 
and hyaline cartilage tissue related with synovial cells (Figure 3). Diagnosis was confirmed as synovial chondromatosis. No recurrence was reported following 16 months post-operatively.

\section{CASE 2}

Fifty five years old female patient admitted to out-patient clinic with enlarging mass on volar side of his left wrist for 2 years. Multiple lobulated mass at the volar side of the wrist beginning from the flexor retinaculum and reaching $8 \mathrm{~cm}$ proximally was palpated in physical examination. No specific findings were present in conventional AP and lateral radiography except minor soft tissue swelling. MRI evaluation stated that $9 \times 4 \mathrm{~cm}$, multiple fusiform shaped nodules were surrounding the flexor tendons and filling the carpal tunnel, nodules were hyperintense in T1 weighted images and isointense in $\mathrm{T} 2$ weighted images.

Identical surgical procedure was applied for the patient. Following the deep dissection, surrounding sac shaped mass is removed and intraoperative puncture of the sac exposed many

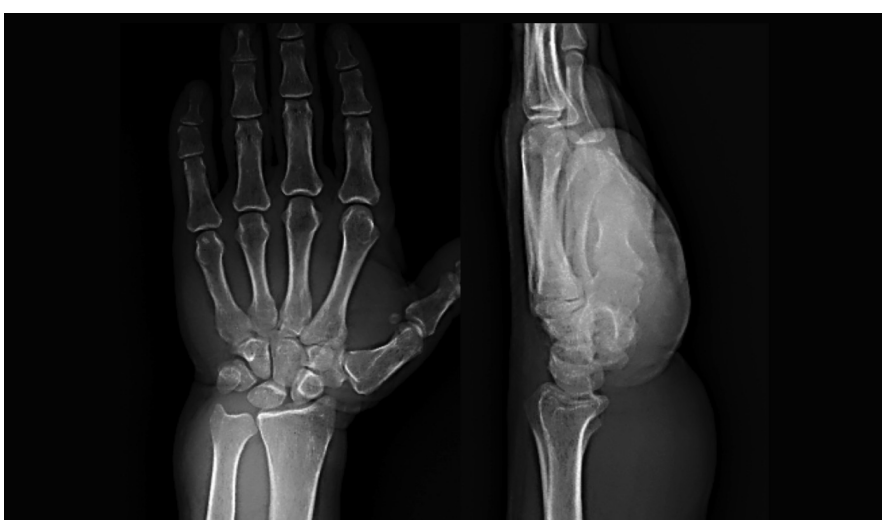

Figure 1. Conventional AP and lateral radiography; there is no specific finding except minor soft tissue swelling

AP: Anteroposterior

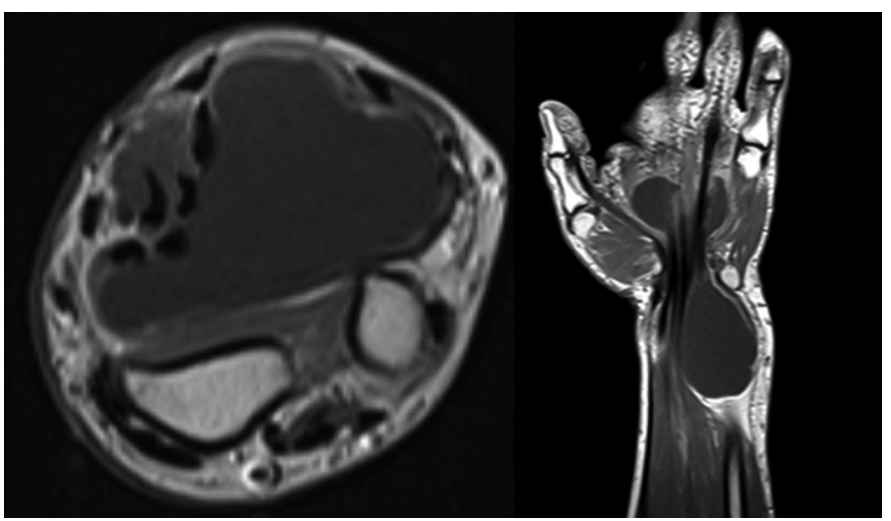

Figure 2. MRI images stated that $12 \times 4 \mathrm{~cm}$ multiple fusiform shaped nodules were surrounding the flexor tendons and filling the carpal tunnel, hyperintense in T1 weighted isointense in T2 weighted images MRI: Magnetic resonance imaging chondroid nodules. Histopathologic examination revealed chondroid nodules covered with synovial and fibrous cells and hyaline cartilage tissue related with synovial cells. Diagnosis was confirmed as synovial chondromatosis. No recurrence was reported following 12 months post-operatively.

\section{DISCUSSION}

Extra-articular synovial chondromatosis is a benign but locally aggressive disease. The most common symptom is a slowly enlarging soft tissue mass. Chief complaint of the both patient was progressively enlarging mass without pain. There is no age or gender predilection for the extra-articular synovial chondromatosis (9). In a literature review by Vinaixa et al. (10) evaluated 30 patients with synovial chondromatosis and there were 12 male, 11 female and 6 patients with misssing data. Vinaixa also stated that 5 out of 30 (17\%) patients had recurrence in 6 to 108 months follow-up. Moreover, even there was no vascular pathology observed 4 out of 30 patients had neurologic complications involving median and ulnar nerve with varying severity. In our cases there is no vascular pathology observed, only in case 1 there is median nerve neurologic symptoms observed.

We introduced 2 new cases to known literature. We had 1 male and 1 female patient with synovial chondromatosis located in carpal tunnel. Even there is no recurrence observed in our cases, expanded follow-up times required to place valid statement about recurrence rates. In our study, we also had no vascular pathology encountered, but first case had prominent median nerve compression signs. Malignant transformation of synovial chondromatosis into chondrosarcoma is an extremely rare event; Vinaixa et al. (10) did not identify any malignant transformation in their review. Davis et al. (11) identified three patients with malignant transformation, from 53 patients with primary synovial chondromatosis and none of these involved

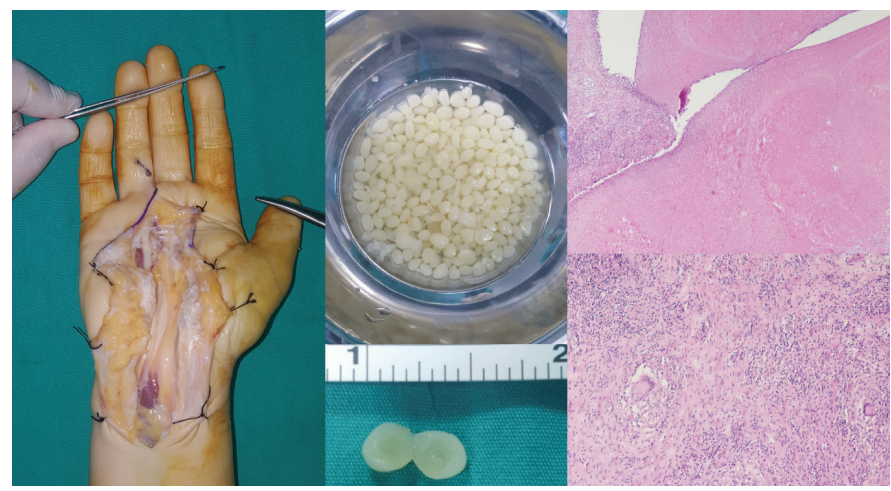

Figure 3. Histopathologic images show that chondroid nodules covered with synovial and fibrous cells and hyaline cartilage tissue related with synovial cells 
the wrist joint. It has to keep in mind that, patients have to be under surveillance for malign transformation for longer period of time even the risk is relatively low.

Clinical diagnosis is not simple because tests often do not give any clear evidence. The most common symptoms are swelling with pain, deformities and reduced joint function caused by compression of the structures (8). Sometimes the clinical picture is silent since there may be no pain or functional limitation but only a lot of swelling without any history of trauma as were the two cases for our patient. After the clinical diagnosis, we proceeded to radiological evaluation. Routine $\mathrm{X}$-ray examination is usually adequate for the diagnosis. X-ray examination shows that soft tissue mass with multiple small calcified or ossified densities (12). But the lack of ossification or calcification of the nodules at the beginning of the disease $\mathrm{X}$-ray did not give anything to diagnosis of the synovial chondromatosis as our cases. If the X-ray is inadequate for diagnosis, MRI will be useful for the diagnosis and clarify the extension of the lesions (12). Conventional radiography provided insufficient data for diagnosis for both cases. Due to the hiperintense appearance in T1 weighted images and isointense presentation in T2 weighted images nodules were not clearly identified. However, these findings in MRI are highly characteristic for synovial chondromatosis (13).

The disease follows three phases, which was described by Milgram (14). In the first phase only active intra-synovial disease exists without loose bodies, in the second stage there are active synovial proliferation and loose bodies are present, and in the third and final stage multiple loose bodies are present without intrasynovial disease. Both of our patients had multiple chondroid bodies and synovial proliferation therefore classified as stage 3 synovial chondromatosis.

\section{CONCLUSION}

In conclusion, we would like to point out those two giant synovial chodromatosis cases localized in flexor compartment. Even typical presentation of the pathology is mostly involved in major joints; extraarticular presentation is also possible and should be considered in differential diagnosis. We recommend long-term follow up for probable recurrence.

\section{Ethics}

Informed Consent: Consent was obtained from patients for this study.
Peer-review: Externally peer-reviewed.

\section{Authorship Contributions}

Concept: I.K., A.E.G., Design: I.K., Data Collection or Processing: I.K., I.H.K., A.E.G., Analysis or Interpretation: I.K., I.H.K., A.E.G., Literature Search: A.E.G., Writing: I.K., I.H.K., A.E.G.

Conflict of Interest: No conflict of interest was declared by the authors.

Financial Disclosure: The authors declared that this study received no financial support.

\section{REFERENCES}

1. Jeffreys TE. Synovial chondromatosis. J Bone Joint Surg Br 1967;3:530-4.

2. Volpin G, NerubayJ, Oliver S, Katznelson A. Synovial osteochondromatosis of the shoulder joint. Am Surg 1980;46:422-4.

3. Murphy FP, Dahlin DC, Sullivan CR. Articular synovial chrondromatosis. J Bone Joint Surg Am 1962;44:77-86.

4. Sah AP, Geller DS, Mankin HJ, Rosenberg AE, Delaney TF, Wright CD, et al. Malignant transformation of synovial chondromatosis of the shoulder to chondrosarcoma: a case report. J Bone Joint Surg Am 2007;89:1321-8.

5. Forsythe B, Lou J, States L, Guttenberg M. Painless ankle mass in a 12-year-old boy. Clin Orthop Relat Res 2004;422:263-9.

6. Young-In Lee F, Hornicek FJ, Dick HM, Mankin HJ. Synovial chondramatosis of the foot. Clin Orthop Relat Res 2004;423:186-90

7. Fetsch JF, Vinh TN, Remotti F, Walker EA, Murphey MD, Sweet DE. Tenosynovial (extraarticular) chondromatosis: an analysis of 37 cases of an underrecognized clinicopathologic entity with a strong predilection for the hands and feet and a high local recurrence rate. Am J Surg Pathol 2003;27:1260-8.

8. Bui-Mansfield LT, Rohini D, Bagg M. Tenosynovial chondromatosis of the ring finger. AJR Am J Roentgenol 2005;184:1223-4.

9. Karlin CA, De Smet AA, Neff J, Lin F, Horton W, Wertzberger JJ. The variable manifestations of extraarticular synovial chondromatosis. AJR Am J Roentgenol 1981;137: 731-5.

10. Vinaixa MMR, Singh R, Monyart JM, Llado GD, Dominguez MP, Feliu EC, et al. Wrist synovial chondromatosis: case report and literature review. Hand Surg 2012;17:233-8.

11. Davis RI, Foster H, Arthur K, Trewin S, Hamilton PW, Biggart DJ. Cell proliferation studies in primary synovial chondromatosis. J Pathol 1998;184:18-23.

12. Walker EA, Murphey MD, Fetsch JF. Imaging characteristics of tenosynovial and bursal chondromatosis. Skeletal Radiol 2011;40:317-25.

13. Ergun $\mathrm{T}$, Lakadamyali $\mathrm{H}$, Aydin $\mathrm{O}$. Multiple rice body formation accompanying the chronic nonspecific tenosynovitis of flexor tendons of the wrist. Radiat Med 2008;26:545-8.

14. Milgram JW. Synovial osteochondromatosis: a histopathological study of thirty cases. J Bone Joint Surg Am 1977;59:792-801. 